\title{
The Investigation of Summer Heat Waves in Tehran City
}

\author{
Behrouz Nasiri \\ Assistant professor, Department of Humanities, University of Lorestan, Lorestan, Iran \\ *Corresponding author Email: Behrouz.nasiriggmail.com
}

Doi:10.5901/mjss.2016.v7n3s2p216

\begin{abstract}
Temperature change trend has been rising in recent years and these changes in areas such as Iran which is located on arid and semi arid belt of world is more impressive. In this research heat waves with different continuations have been studied for Tehran metropolis in a 5 years period (2010-2015). Statistical data of mean daily temperature of synoptic stations of Tehran in the summer were selected and then a few continuing days temperature that were higher temperature trend than mean temperatures of before and after days defined as a heat wave that had continuation of 3 to 6 days. After extraction the days with heat wave, synoptic maps of geo potential and humidity, as well as indexes, charts Skew T of days for governing phenomenon were provided. The results showed that most of the heat wave phenomena have happened in July. In the terms of synoptic view, the occurrence time of this phenomenon in most cases has been when high pressure subtropical prevailed and has higher elevations than its mean long-term and has created a stable atmosphere for the Tehran metropolitan. On the other hand tabs of moisture have entered below the surface of the high-pressure to atmosphere of region has been caused the temperature increase and intensify it.
\end{abstract}

Keywords: Tehran, heat waves, GRADS, Skew T

\section{Introduction}

Today in the issue of global climate change, the most important issue, is the issue of increasing the Earth's temperature. Since temperature is one of the main elements of climate forming, its changes can cause change at different spatial scales. At global scale since twentieth century we are observing an increase of 0/6 degree of air temperature (WMO, 2003) and this is probably the maximum temperature during the past 1000 years has occurred in the northern hemisphere (Christian coupe et al., 2004) and on a smaller scale for Iran during the past hundred years, an increase of 2 degrees day and night temperature has been approved (Masoodian, 2004).

The Prediction of an increase to 2.75 degrees Celsius of temperature in regional scale for north east of Iran and Khorasan province is indicative of the temperature rise in regional scale (Alizade and kamali, 2002). Multi-day deployment and unexpected high temperature air in a region which is more than of its long-term average temperature is said as the heat wave. Intense heat waves, is considered as a climate risk, but its expansion is slow, unlike the Storms. In this field many research have been conducted, including the study of Xiao and colleagues in 2003 that have shown the increase in the minimum temperature in East Asia.

Demers and Tantawi also in a study have proven an increase of 7.0 degrees in temperature in Africa continent. Also for metropolitan Tehran, the increase of mean annual temperature of at least $0 / 68^{\circ} \mathrm{C}$ has been shown (Bidokhti and Saadat Abadi, 2003). In 2006, Jolie Diaz and colleagues conducted a study to examine the effects of heat waves on human life and came to the conclusion that to prevent the loss of heat waves on human life for at least two days before it heat wave should be detected, otherwise, with higher threshold of temperature mortality would be increased.

According to the World Meteorological Organization in the years 1975 to 1936 nearly twenty thousand people died due to heat wave and solar shine in America. The resulting losses of this phenomenon in 1980 were more than 1,250 people (WMO, 2002).

In 1995 in Chicago the occurrence of a severe heat wave led to more than five hundred deaths and accompanied with large financial losses and after this event the phenomenon of heat wave was considered as one of the hazards of climate by researchers and scientific centers (kunkel et al, 1996; klinenberg, 2002).

In 1996 in America, Changnon showed in a study that the effects of heat waves in the central part of the city due to the role of heat island have been more and is 2 degrees above than its surroundings. August 2003 heat wave in Europe killed more than 35,000 people (Vandentorren et al; 2004).

McFarlane in 1978 in the UK studied the positive changes in temperature and increase in continuous hot days in a 
row with an increase in respiratory and cardiovascular diseases and strokes caused by psychological stress caused by rising temperatures that showed effects of it has increased in people over age 60. Pascal also in Ireland in 2011 in relation to the heat waves and human health conducted a research that during the period of 22 years of this study approximately 254 people died as a result of the heat wave and it was showed that the percentage of rural residents and the suburbs vulnerability relative to the center of the city has been much less. Irish researchers have predicted that given the prospects ahead due to climate change and an aging population, heat wave losses will be more in the future (Pascal, 2011). Vaneckova in 2008 has shown that the loss of life in consecutive hot and dry days has been more than consecutive hot and humid days. In terms of synoptic studies it can be referred to Rusticucci study. He conducted surveys about the heat wave in Argentina in March 1980 and showed that the continuation of an anti-cyclone extension at all levels of the troposphere has been the main cause of rising temperatures. Kolasino and colleagues in 1994 studied the amount of temperature rise and its consequence as heat waves on the Mediterranean region and they divided them into two long and short wave and with 42-year-old statistical analysis concluded that there is an association between anticyclonic patterns and the development of heat wave in the studied region. In 2003, a severe heat wave occurred across South America that air temperature reached up to $44^{\circ} \mathrm{C}$ and on the basis of synoptic studies it is showed that stable atmosphere and the advection of temperature and humidity have been the causes of heat wave creation and intensification (Seluchi, 2009-2010). Since the heat waves causes extensive damage to agriculture and human health and reduce comfort climate of human in metropolises like Tehran, the aim of this study id to determine the temperature trend in Tehran metropolis that has been performed using a statistical index called the heat wave and by evaluating the synoptic conditions governing it we can predict the occurrence of this event because the most important way to prevent deaths from dangerous climate phenomena is prediction of them.

\section{Materials and Methods}

In this study, firstly statistical data of mean daily temperature of synoptic stations of Tehran from Meteorological Agency of country was prepared and designed. Then warm season data in this city which includes the months of june, july, august and september were extracted and continuous days with increasing trend and compared to the mean of before and after days have great changes have been selected as the heat wave, then in the Excel software, frequency graph of occurrence of heat waves for all the months was plotted followed by geopotential maps of $500 \mathrm{hp} \mathrm{level} \mathrm{and} \mathrm{special}$ moisture maps or (shum) for the 850hp level using the software GRADS that was prepared for the given days and its results were interpreted. Also Skew $T$ graph of them were taken for two hours $00 z$ and $12 z$ from University of Wyoming and was interpreted.

\section{Air Mass Affecting Tehran Climate in the Warm Season}

\subsection{Azores high pressure}

Subtropical high pressure centers that are separate cores on the margins of the Tropic of Cancer and Capricorn are created due to ongoing subsidence of air in the middle levels of the atmosphere. One of these cores is high pressure core of Azores that on the Azores archipelago is formed by dynamic subsidence. During the warm season, coinciding with the withdrawal of western and northern winds flow, this high pressure govern on the entire country of Iran as well as Tehran's and block the entry of wet and rainy mass and creates a calm and clear atmosphere with high solar radiation for Iran.

\subsection{Iran's central desert heat low pressure}

During hot periods of the year due to more solar radiation caused by angle and duration of radiation-induced increase in central Iran, especially the desert, in southern margin of Elborz mountains, strong thermal center is created that moves its heat waves to large parts of the country including Tehran from the south and southwest, and contributes to intensification of dryness of air and a lot of air heating.

Table 1. Date of occurrence of heat waves in Tehran during 5-year period (2010-2015)

\begin{tabular}{|c|c|c|c|}
\hline Year & \multicolumn{3}{|c|}{ Date of accurrence of heat waves } \\
\hline 2015 & $8-11$ july & $17-21$ august & $26-30$ june \\
\hline 2014 & $4-16$ & $11-13,18-21$ & $3-7$ \\
\hline
\end{tabular}




\begin{tabular}{|c|c|c|c|}
\hline 2013 & $9-15,25-29$ & $4-6$ & $25-29$ \\
\hline 2012 & $5-8,11-13$ & $6-9,15-17$ & $6-10$ and 28june-2july \\
\hline 2011 & $5-9,14-16,21-25,26-28$ and 31 july-2august & $4-6$ & $15-18$ \\
\hline
\end{tabular}

\subsection{Seasonal distribution of heat waves in Tehran}

Tehran situation is such that in different seasons under different climate factor is hot and cold. From mid-spring in this city, coinciding with the start of the Azores subtropical high pressure regime, the city heating season begin and some days because of several factors that will be explained, the air temperature rises as a risky phenomenon and stays stable for multi-day that is known as heat wave. In terms of monthly according to Figure 1, we see that during the 5-year period, heat wave event starting from June and peaks in July. This phenomenon continues to August and since then suddenly stops and this is due to the withdrawal of the Azores high pressure to low latitudes and starting of western and northern cool and humid air mass entry into the city.

The mean incidence of heat waves in the warm season is eight which in a period of 3 to 6 days affects the climate of the city. In other months of the year no cases of this phenomenon has been seen in over a five-year study period.

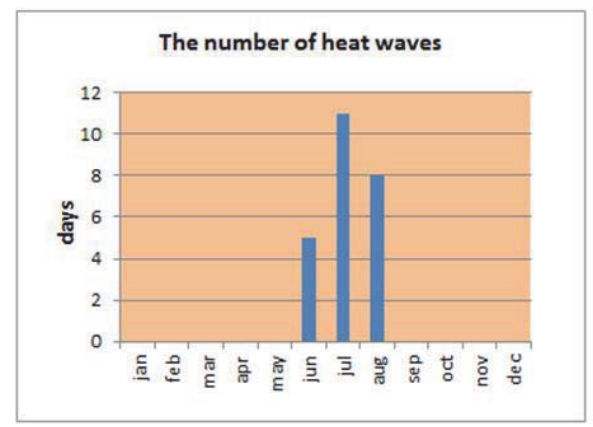

Figure 1. Time distribution of heat waves in the months of the year (the period 2010-2015)

Table 2. The maximum temperature during heat wave

\begin{tabular}{|l|c|c|c|c|c|}
\hline Station & 2015 & 2014 & 2013 & 2012 & 2011 \\
\hline chitgar & 41 & 39.4 & 38.4 & 37.2 & 37.11 \\
\hline Doshantapeh & 40.8 & 40.6 & 39.6 & 38.16 & 39.9 \\
\hline geophysic & 38.8 & 38.5 & 38.4 & 36.5 & 37.8 \\
\hline Tehran north & 38.9 & 38.8 & 38.5 & 36.3 & 37.9 \\
\hline mehrabad & 40.6 & 38.5 & 40.3 & 38.4 & 40.43 \\
\hline min & $\mathbf{3 8 . 8}$ & $\mathbf{3 8 . 5}$ & $\mathbf{3 8 . 4}$ & $\mathbf{3 6 . 3}$ & $\mathbf{3 7 . 1 1}$ \\
\hline
\end{tabular}

Due to values of Table 2 in the can be seen temperature changes during the five years and only in two years of 2011 and 2012 there is a slight downward trend, that are very small amounts. But in a general perspective an upward trend can be observed. Among the stations studied, since Mehrabad station has airport position and airplane traffic on it is high, maximum mean temperature of it over time is high.

\subsection{Synoptic analysis of heat waves}

According to studies, it has been shown Tehran metropolis heat waves govern 3 to 6 days and in this sense have their origin should be examined in a wider scale and as a synoptic review. Based on geo potential maps of Figure 2 and 3 we see that the Azores high pressure has an important role in causing this phenomenon and is located exactly on Iran has impressed it entirely and in more than $90 \%$ of days with this phenomenon, the Azores high pressure has been predominate. And as can be seen in Figure 3 Tehran is located in front of wave drop axis. So is impressed with weather of lower latitudes and hot air of deserts of North Africa and Saudi Arabia with southwest-northeast to be drawn to high 
latitudes and are Tehran and increases air temperature dramatically. These high-pressures have a barotropic or stable governor and creates a barrier to rising air and in this case, there is just clear and calm air with governance of warm sun radiation in the atmosphere in this area and if the atmosphere has a lot of moisture, condensation and rain are not happen and only exacerbates the temperature rise.

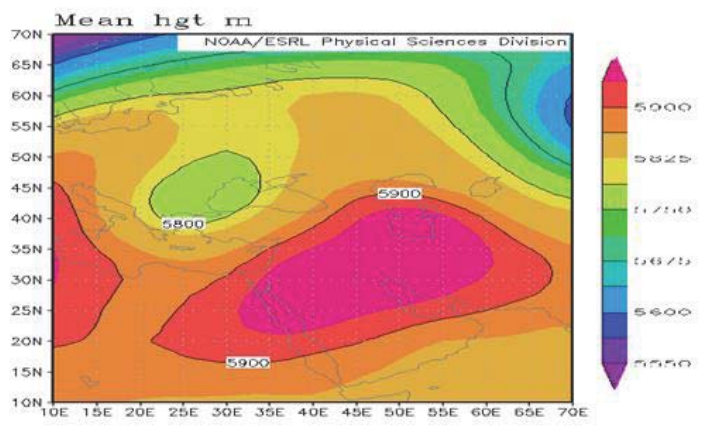

Figure 2. Map of geopotential of $500 \mathrm{hp} \mathrm{level} \mathrm{(9-15} \mathrm{july} \mathrm{2013)}$

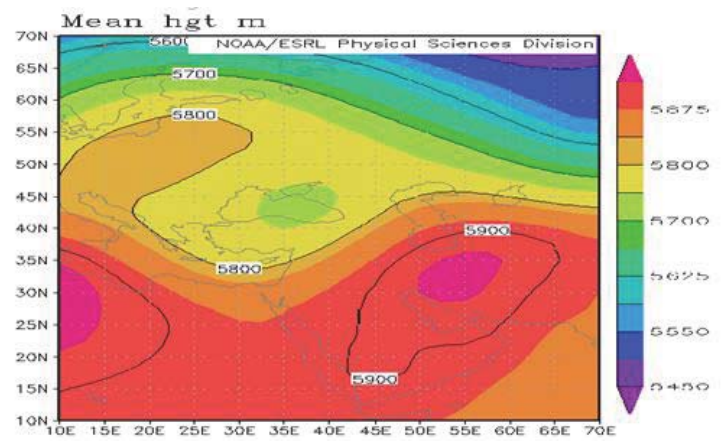

Figure 3. Map of geopotential of $500 \mathrm{hp} \mathrm{level} \mathrm{(26-30} \mathrm{June} \mathrm{2015)}$

According to Figure 4, we find that in addition to Tehran in the hot period of the year is under the rule of the Azores high pressure, at the lower level of it an amplification factor plays a role in increasing the air temperature and creation of heat waves that is humidity. Based on the figure we see that in most cases in which this phenomenon has been exacerbated the influence of moisture in it is outstanding and from this we can see that at levels close to the earth, ( $850 \mathrm{hPa}$ level) tabs of high humidity enters to city from the northwest and since the governance of high pressure has prevented rise condition creates a sultry air and through a greenhouse form with coming solar short-wave and non-return of the long wave, causes intensification of rise in temperature. This phenomenon exists in most days that predominance of heat wave is long. Although Azores high pressure has high height and this height provides the conditions for the penetration of moisture tabs at low levels provides but not enough for rise and density and moisture is only aggravating factor of the air temperature. 


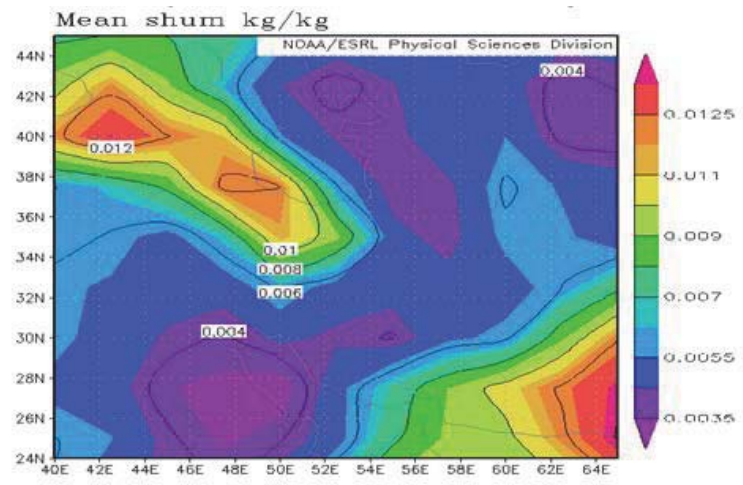

Figure 4. Specific humidity at $850 \mathrm{hPa}$

Based on the skew $t$ graphs (Figure 5-6) for two times 00z and 12 z15jul 2013, ascending air density level (LCL) were calculated for the mentioned hours. The LCL level is a level at which ascending air package reaches saturation and condensation takes place and its lower height, provide a better position for the formation and growth of cloud and instability for the air pack. The results show high levels of LDL in 00 o'clock are lower $39.1 \mathrm{~mm}$ compared to 12 o'clock on 15 July. These conditions represent the perfect situation of instability at 12 o'clock. The level of free convection (LFC) is usually higher than the LCL. On this day because of technical problems height of this level has not been reported. According to CAPE index values at 00 and 12 o'clock weather conditions had been in a poor unstable condition. According to the numerical values of Showalter Index (SI) on 15 July (5.41), 00 o'clock indicating no occurrence of condensation and convective precipitation. That amount has dropped at 12 o'clock at a rate of 4.15 and is a predictable and stable atmosphere. Low values of $\mathrm{KI}$ index indicating no movement of convection. According to calculations TTI value on 25 July during the hours of 00 and 12 shows a low probability of occurrence of convective motions. Calculated index values for $\mathrm{LI}$ rise index reflects stability of air on 15 July and decrease and increase the close temperature with dew point temperature in the atmosphere. The calculated values for SWEAT index also suggest stability of air for the studied region. This index usually is used in regions that are vulnerable to storms. According to Table 3 and abovementioned about the atmospheric instability it is turned out that the values of studied indices on 25 July 2013 confirmed the stability of the air and the lack of the convective motions in the studied region.

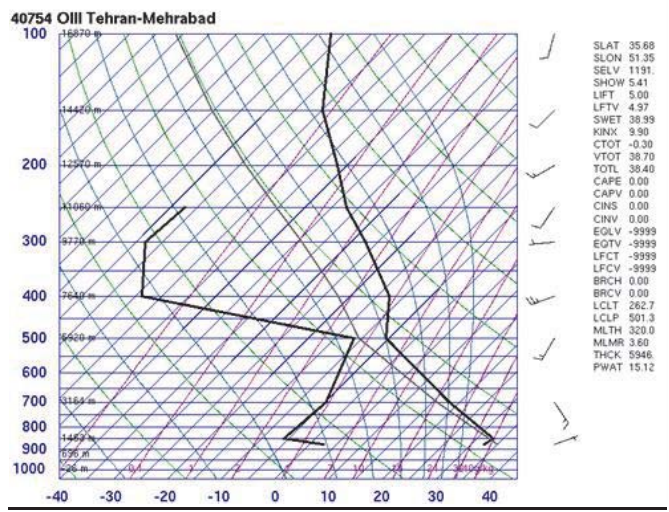

Figure 5. Graph of skew T 00z at Mehrabad station (15 jul 2013) 


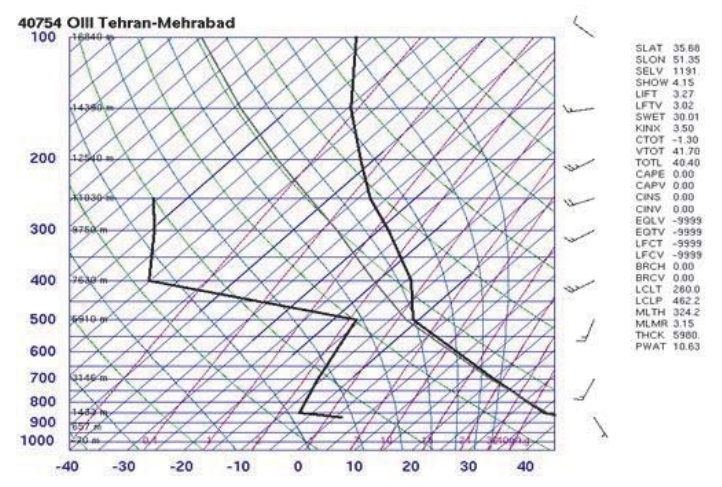

Figure 6. Graph of skew T 12 z at Mehrabad station (15 jul2013)

Table 3. Estimates of the incidence of heat waves on 15 July 2013

\begin{tabular}{|c|c|c|}
\hline index & (utc) 12 & (utc) 00 \\
\hline$L C L$ & 462.2 & 501.3 \\
\hline$L F C$ & -9999 & -9999 \\
\hline$C A P E$ & 0 & 0 \\
\hline$K I$ & 3.50 & 9.90 \\
\hline$T T I$ & 40.40 & 38.40 \\
\hline$L I$ & 3.27 & 5 \\
\hline$S W E A T$ & 30.01 & 38.99 \\
\hline$P W(m m$ & 10.63 & 15.12 \\
\hline$S I$ & 4.15 & 5.41 \\
\hline
\end{tabular}

\section{Conclusion}

To evaluate the general conditions heat wave governing on the region, the mean daily temperature data in the synoptic stations in Tehran were used. Then data during 5-years period (2010-2015) was ordered and days for several days their temperature was above the monthly mean, were identified as heat waves and during the period around 24 heat waves were detected that had continuations of 3 to 6 days. These waves seasonally happen only in the warm season for metropolitan Tehran that's why this season's waves were examined. The studies showed that the incidence time of heat waves starting from the month of June, and peak on July and reach to number 11 and continuing until the month of august. The synoptic view of waves in the upper atmosphere, geopotential maps for $500 \mathrm{hp}$ and shum level of $850 \mathrm{hp}$ were produced based on which origin of these waves was determined and showed that whenever the Azores subtropical high pressure is placed higher altitudes than its long-term mean on region atmosphere and at the lower level, the tabs of moisture come into the region atmosphere, extreme heat waves would happen in which subtropical high pressure has a major role in its occurrence and humidity also plays a resonator role, and thus heat wave is intensified. Interpret the Skew T graphs for the day 15 July 2013 , also show quite air stability that air convection moves in it is zero.

\section{References}

Alizadeh,amin and golamalikamali,(2002).Effects of climate change on agricultural water consumpation in mashhadplain.geographical research.no 66.

Bidakhti,aliakbar, abasaliranjbar and abbassaadatabadi,(2003).Effects of climate heat island Tehran.proceedings of the Third regional conference on climate change.Esfahan.

Changnon S.A, Kunkel K.E and Reinke B.C (1996): Impacts and responses to the 1995 heat wave: A call to action. Bulletin of the American meteorological society $77: 1497-1506$.

Colacino, m (1995) Heat wave in the Central Mediterranean A Synoptic Climatology instituted di fisica dell' Atmospheric fear (CNR) Roma .Italy.vol.18c.3.

Diaz, Julio, Cristina, Linares and Aurelio, Toby's (2006) A Critical comment on heat Wave response plans. European Journal of 
publication health vole, 16 no. 6, 600 .

Domroes Manfred, El-TantawiAttia(2005) Recent Temporal and Spatial Temperature Changes in Egypt. Int. Journal of Climatology, 25.

Klinenberg, E. (2002). Heat wave: A social autopsy of disaster in chicago. Chicago, IL:chicago university press.

Koppe, Christina, Sari Kovats, GerdJendritzky and Bettina Mennen (2004) Health and Global Environmental Change ,publication, WHO, Regional office for Europe scherfigsvej 8 ,DK 2004 Copenhagen, Denmark's 6.

Kunkel KE, Changnon S.A ReinkeBC,Arritt RW. (1996): The July 1995 Heat wave in the Midwest: A climatic perspective and criticale weather factors. Bulletin of the American meteorological society 77:1507-1518.

Macfarlane, A.(1974). Daily mortality and environment in English conurbations. II. Deaths during summer hot spells in greater London. Environmental Research 15, 332-341.

Masoodian,saidabolfazl,(2004).evaluation of temrature trends in the past half century.journal of geography and development,no 3 .

Pascal, Mathilde (2011). TitleAn Analysis of the Mortality Risks Associated with Heat and Heat Waves in Ireland, to Assist in Planning for Climate Change. Doctoral Thesis. Dublin Institute of Technology, 2011.

Rusticucci, M. \& Vargas, W. (1995). Synoptic situations related to spells of extreme temperature over Argentina. Meteorol. Appl., 2: 291-300.

Seluchi ،M; F ‘Norte; J ،Gomes; S ،Simonelli ، (2006) ،Synoptic and thermodynamic analysis of an extreme heat wave over subtropical South America ‘Proceedings of ICSHMO ‘Foz do Iguaçu ‘Brazil ‘April 24-28 ‘2006 ،INPE ‘p 2009-2010.

Vandentorren S, Suzan F, Medina S, Pascal M, Maulpoix A, Cohen J-C, Ledrans M (2004) Mortality in 82 French cities during the August 2004 heat wave. Am J Public Health 94:1518-1520.

WMO,2002: Guide on the Application of new technology and researchto public weather Service, WMO/TD no.1102, PWS-6.

Word Meteorological Organization, 2003 : guide to climatological practices second edition, WMO, no 100.

Zhao Zong, SumiAkimasa, Harada Chikako, NozawaTotu (2003) Projections of Extreme Temperature Over East Asia for the 21 stCentury as Simulated by the CCSR/NIES2 Coupled Model; Proceeding of the International Symposium on Climate Change (ISCC). Beijing: China. 